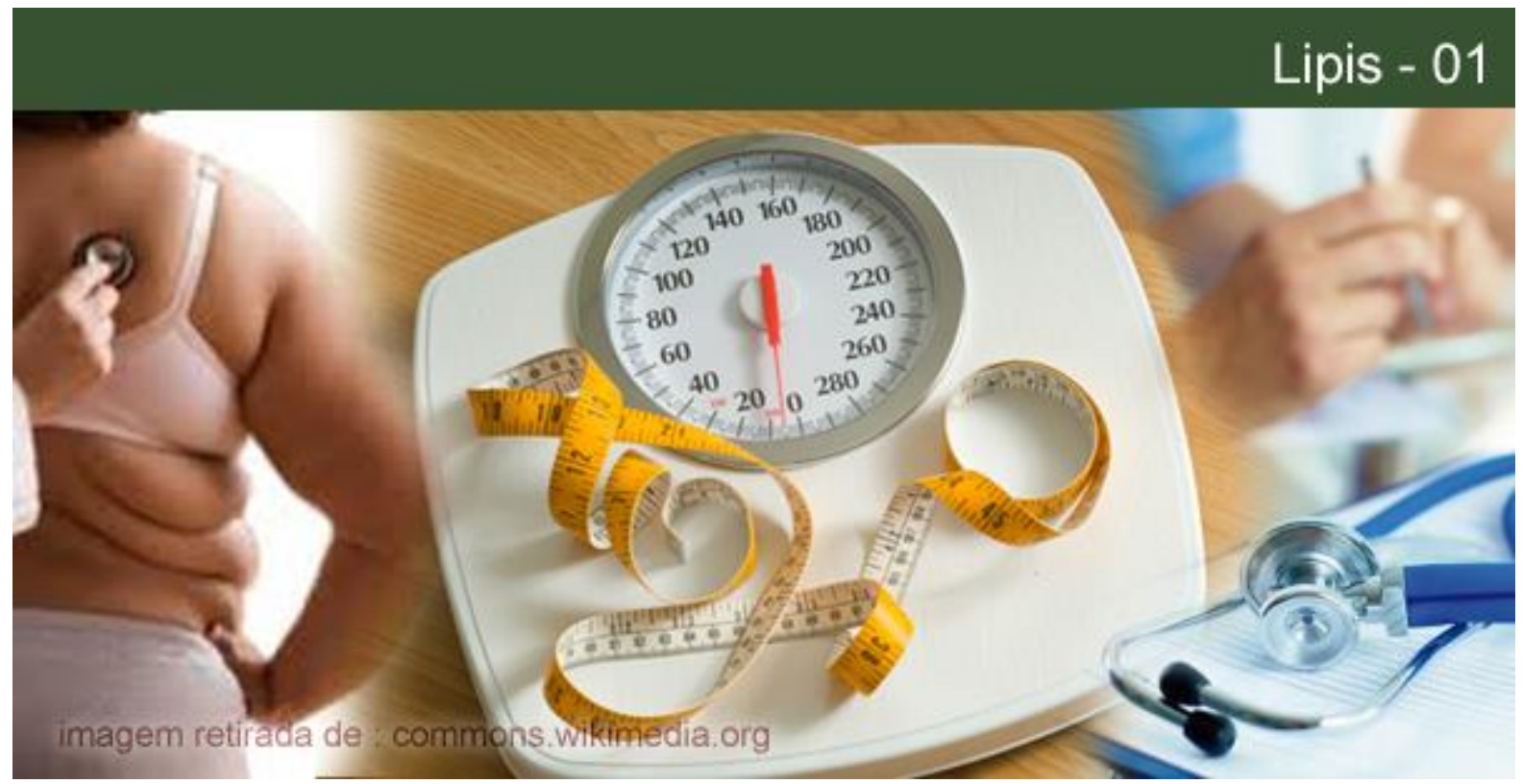

\title{
O ALIMENTO E A PALAVRA: OBESIDADE, UMA LEITURA PSICANALÍTICA
}

\section{Vera Pollo}

Psicanalista. Doutora e Mestre em Psicologia pela Pontifícia Universidade Católica - PUC-RJ; D.E.A. pela Université de Paris VIII, Saint-Denis. Analista membro da Escola de Psicanálise e da Internacional dos Fóruns do Campo Lacaniano (AME da IF-EPFCL). Membro do Colegiado de Formações Clínicas do Campo Lacaniano-RJ. Professora Titular do Programa de Pós-graduação stricto sensu em Psicanálise, Saúde e Sociedade da Universidade Veiga de Almeida e da Especialização em Psicologia Clínica da PUC-RJ. Exerce a clínica no Núcleo de Estudos da Saúde do Adolescente [NESA/HUPE/UERJ] e em consultório. Organizadora de "Comunidade analítica de Escola: a opção de Lacan" (Marca d'Água Livraria e Editora, 1999); autora de "Mulheres histéricas" (Contra Capa Livraria, 2003) e de "O medo que temos do corpo" (Editora 7Letras, 2012).E-mail:verapollo8@gmail.com.

\section{Elizabeth Matta da Cunha Pessoa}

Psicóloga clinica. Especialista em Psicologia Hospitalar. Mestre em Psicanálise, Saúde e Sociedade pela Universidade Veiga de Almeida - UVA (Rio de Janeiro, RJ, Brasil). Psicóloga integrante da equipe do Serviço de Psicologia Médica do Hospital Federal dos Servidores do Estado - RJ, responsável pelo atendimento psicoterápico de pacientes portadores de transtornos alimentares. E-mail: emcpessoa@bol.com.br / bethinhapessoa@hotmail.com.

Resumo: O presente artigo discorre sobre a relação do alimento e da palavra através do tema da obesidade. Inicia com um breve relato histórico da emergência do fenômeno e prossegue com a narrativa de um tratamento que consistiu em um percurso exitoso de ultrapassagem da obesidade por meio do atendimento em grupo e individual no setor de Psicologia de um hospital público e de cirurgia bariátrica. Na terceira parte, o artigo propõe uma leitura psicanalítica discorrendo sobre três deduções: a coexistência de dois desejos antinômicos, sem perda da sustentação narcísica do sujeito; a coalescência oral/escópica favorecendo a materialização do corpo na palavra; a travessia da devastação mãe/filha. Por fim, conclui que trata-se de fatores subjetivos a serem pesquisados em todos os casos de obesidade feminina.

Palavras-chave: Obesidade. Desejos antinômicos. Sustentação narcísica. Coalescência oral/escópica. Devastação mãe/filha.

\section{POLÊM!CA | Revista Eletronica da aej}


THE FOOD AND THE WORD: OBESITY, A PSYCHOANALYTICAL READING

Abstract: This article tackles the relationship between food and word through the issue of obesity. It begins with a brief historical account of the emergence of the phenomenon and it proceeds with the narrative of a case. The treatment proved to be quite successful as the patient managed to overtake obesity as she went through group and individual treatment, which took place in the Psychology Department of a public hospital. Besides that, she also went through bariatric surgery. In the third part, the paper proposes a psychoanalytic reading through the discussion of three main deductions: the coexistence of two opposite desires, but with narcissistic support; oral / scopic coalescence promoting the materialization of the body into the word; the trespassing of the devastation between mother and daughter. Finally, it can be concluded that such subjective issues must be taken into account in all cases of female obesity.

Keywords: Obesity. Opposite desires. Narcissistic support. Oral / scopic coalescence. Mother-daughter devastation.

\section{Introdução}

A humanidade sempre lidou com questões de sobrevivência, principalmente no que se refere a comer/devorar e a ser devorado/comido. Como salienta Pizarro Obaid (2014, p.543), a hipótese de uma oralidade canibalística é bem antiga e as crônicas da descoberta do Novo Mundo, que fizeram do 'canibal' a figura paradigmática do 'antropófago', divulgaram-na no continente europeu. Porém, a crermos nos historiadores, o fenômeno da obesidade seria ainda mais antigo, datando verdadeiramente dos primórdios da civilização.

Derivada do vocábulo latino obesîtas, a palavra "obesidade" é composta pelo prefixo ob, que significa "em", "por" ou "sobre", e pelo particípio passado do verbo edere, comer ou devorar. Em latim, obesus significa completamente nutrido, nutrido em excesso (CUNHA, 2010). De acordo com a Organização Mundial de Saúde (OMS), a obesidade pode ser definida como "uma doença na qual existe uma acumulação excessiva de massa gorda, de tal forma que a saúde pode ser adversamente afetada" (ROMANELI, 2006). Todavia, por não ter sido estabelecida uma associação consistente entre a obesidade e uma síndrome específica, psiquiátrica e/ou comportamental, o manual diagnóstico (DSM-IV) da Associação Americana de Psiquiatria não a inclui entre as formas de transtorno alimentar. Isso significa dizer que a obesidade não é considerada uma patologia psiquiátrica.

Em agosto de 2010, o Instituto Brasileiro de Geografia e Estatística (IBGE) publicava os resultados de uma pesquisa indicando que, desde a primeira pesquisa familiar, registrando peso e altura dos entrevistados, em 1974, o excesso de peso em homens adultos havia saltado de $18,5 \%$ para $50,1 \%$, e o das mulheres de $28,7 \%$ para $48 \%$. Tais resultados foram lidos como a expressão de uma epidemia, já que a metade da população adulta masculina e quase a metade da população adulta feminina podiam ser consideradas obesas. As pesquisas 
subsequentes com a população infantil e infanto-juvenil apresentaram resultados semelhantes. Próximos aos das pesquisas norte-americanas, estes resultados começam a exigir não apenas estudos médicos, como também sociológicos, psicológicos e psicanalíticos.

O presente artigo objetiva apresentar uma leitura psicanalítica do fenômeno da obesidade individual, contextualizando inicialmente o momento da emergência do fenômeno no campo médico e prosseguindo com a narrativa de um tratamento em que se evidenciam mudanças significativas nas relações do sujeito com o real do próprio corpo e com o Outro social.

\section{A emergência do fenômeno}

Embora não se possa comprovar a existência de indivíduos obesos na pré-história de forma absolutamente inquestionável, a suposição de tal fenômeno baseia-se no fato de que estatuetas femininas e desenhos rupestres que apresentam características humanoides com excesso de peso já foram encontrados em diferentes sítios arqueológicos. Arqueólogos e historiadores se encontram diante da impossibilidade de afirmar se essa representação pictórica estaria relacionada à escassez de alimento, devendo funcionar a título de amuleto, ou se representaria projetivamente a fecundidade e a fertilidade, por apresentar mamas, órgãos genitais e abdômen hipertrofiado. Um belo exemplo de estatueta pode ser visto na Vênus de Willendorf, descoberta na Áustria, em 1990.

Figura - 1: Vénus de Willendorf (Museu de História Natural de Viena).

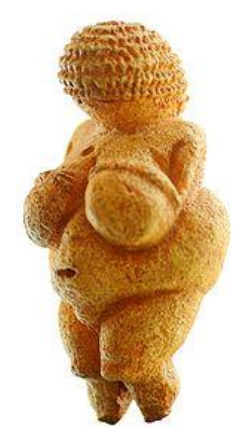

Na passagem da pré-história para a Idade Antiga, há evidências de obesidade em múmias egípcias, esculturas gregas e pinturas em vasos antigos (REPETTO, 1998). Também, nessa época, alguns textos hipocráticos revelam que a obesidade já se apresentava como um

\section{POLÊM!CA | Revista Eetrônica da veri}


tema digno de reflexão (INBIO, 1998). Neles, Hipócrates (460 - 370 a.C.) descreve que a morte súbita era muito mais frequente nos pacientes gordos e observa que as mulheres gordas eram menos férteis que as magras, sendo a infertilidade atribuída às dificuldades na cópula e ao acúmulo de gordura fechando a entrada do útero. Galeno (129 - 200 d.C.) identificou e descreveu dois tipos de obesidade: a moderada e a imoderada. A primeira, uma forma natural de gordura, e a segunda, uma forma patológica. Para ele, evitar a gordura seria verdadeiramente uma arte, da qual apenas as pessoas 'obedientes' seriam capazes.

No período medieval, a obesidade já era plenamente conhecida. Começaram a surgir novos autores na área da medicina com interesse no tema, como Avicenas (981 - 1.037 d.C.), médico influente da cultura árabe (GILMAN, 2010). No campo da religião, a concepção de obesidade guardou diferentes significações simbólicas. Para os judeus, o corpo obeso era um desvio que se caracterizava como falta de autocontrole e poderia sofrer punição, embora não fosse exatamente um pecado (GILMAN, 2010). Para os cristãos ocidentais, era fundamental controlar o apetite, segundo a noção, iniciada pelo discípulo Paulo, de que o corpo era templo de Deus. Com a supremacia da igreja católica na Idade Média, o corpo obeso passou a ser sinal de falha no relacionamento com Deus e com o complexo mundo divino. Surge então a gula como um dos pecados mortais na tradição cristã (GILMAN, 2010).

Em associação aos campos médico e religioso, o campo político-social participou e participa ainda da construção conceitual da obesidade. Como a experiência da fome foi vivenciada por todas as sociedades da Europa Medieval, a abundância alimentar transformouse em fato social que traduzia riqueza e superioridade (FLANDRIN; MONTANARI, 2008). Com o evento das Cruzadas, a retomada das viagens restabeleceu o contato com as culturas árabes e greco-romanas do período clássico, dando início ao período renascentista no qual a compreensão cristã da gula sofreu as suas primeiras modificações.

No século XVI, em meio a uma lenta evolução, a literatura sobre a obesidade reforça a noção de que comer com prazer pode gerar doença, distanciando os conceitos de desejo/prazer e comida (FLANDRIN; MONTANARI, 1998). No século seguinte, com o surgimento da literatura sobre os alimentos (saudáveis ou insalubres), as questões morais perdem gradativamente sua conotação religiosa. A quantidade perde espaço para a qualidade e aumenta o interesse médico pela obesidade, que passa a ser investigada a partir dos conhecimentos anatomopatológicos, inclusive através de dissecações de cadáveres de 
indivíduos obesos. J. L. Flandrin, historiador francês, resume a história da obesidade com a seguinte frase: "Não foi a guerra entre a teologia e a ciência, mas sim sua integração pública que foi fundamental para a história da obesidade" (FLANDRIN, 1998, p.547).

$\mathrm{Na}$ época do Iluminismo, a gordura corporal tinha um significado que estava além do anatômico, indicando falta de equilíbrio (GILMAN, 2010). Mas, somente em fins do século XVIII, portanto, nas portas do século XIX, agregou-se à obesidade o significado de fraqueza psicológica. Sobreposta à problemática moral, social e/ou psicológica, a obesidade se afirmou como um problema médico, caracterizando-se como uma patologia da qual a medicina moderna não poderia fugir. Observou-se, então, expressivo aumento no número de medicamentos para a obesidade. Descobertas médicas, como a divisão da obesidade em endógena e exógena, e o amplo estudo de casos levaram ao conhecimento de outras causas orgânicas para a obesidade, como desordens genéticas e distúrbios endocrinológicos (BRAY, 1998).

Após a Segunda Guerra Mundial, surgem os estudos interdisciplinares e o protocolo do IMC - Índice de Massa Corporal, de Lambert Adolphe Jacques Quetelet, definindo um modelo matemático para mensurar a gordura individual, que é válido até os dias de hoje (ANJOS, 2006). A Associação Brasileira para o Estudo da Obesidade e da Síndrome Metabólica (ABESO) utiliza o sistema de classificação de Quetelet, o qual, como mencionado acima, acusa índices assustadores, requerendo estudos de diferentes campos do saber.

Uma pequena nota do Caderno Saúde do jornal O Globo, de 23 de março de 2014, dizia exatamente o seguinte:

Pesquisa na Universidade McGill, no Canadá, apresentada em conferência da American Heart Association, relaciona o rigor na criação das crianças com a obesidade infantil. Segundo o estudo, a epidemia de obesidade que atinge os países em todo mundo poderia ser amenizada se pais e filhos tivessem um relacionamento melhor. Quanto mais afeto for dispensado às crianças, argumenta, menor a propensão ao excesso de peso. (O GLOBO, 2014).

Parece-nos coerente afirmar que a obesidade é hoje um sintoma social, tal como o entende a psicanálise: um significante enigmático que incide no real dos corpos. Freud observara, em 1937, que o sintoma não é propriamente a expressão de um mal-estar $d a$ cultura, mas o índice de um mal-estar na cultura. É justamente na falha do saber médico sobre as causas e o tratamento da obesidade, que ela se revela simultaneamente como índice do malestar na cultura contemporânea e como a verdade de um sujeito. 


\section{Um tratamento exitoso}

Em contraposição à maior parte dos casos, chamados na clínica hospitalar em que trabalhamos ${ }^{1}$ de "casos de transtorno alimentar", particularmente os de obesidade mórbida, que se apresentam quase invariavelmente resistentes e plenos de histórias de recidiva, Maria ${ }^{2}$ apresentou um percurso exitoso em termos de emagrecimento, motivo pelo qual decidimos analisá-lo em detalhes. Ela chegou para o primeiro encontro, em 2007, sem nenhum encaminhamento médico ou nutricional. Aos 32 anos, com apenas 1,47 $\mathrm{cm}$ de altura, pesava $127 \mathrm{~kg}$. Atualmente, com 38 anos, está pesando $65 \mathrm{~kg}$.

Caçula de uma família de cinco filhas, Maria falava do pai de forma carinhosa. Costumava dizer que ele se identificava mais com ela do que com as outras filhas, porque ela era diferente, mais inteligente do que as demais. Ela e o pai saíam juntos frequentemente com propósitos de lazer, por exemplo, para soltar pipas. Descrevia a mãe como uma pessoa que não transava bem esse lance do contato físico e costumava lhe dizer que sua corpulência era herança genética da família do pai.

Narrou uma adolescência tranquila, pois, apesar de nunca ter sido magra, não havia problemas com o excesso de peso naquela época de sua vida. Quando morou em um pensionato de moças, seu pai foi duas vezes visitá-la, diferentemente da mãe, que jamais apareceu por lá. Ao terminar o ano letivo, voltou para a casa dos pais e começou a trabalhar com o pai no ramo dos serviços de alimentação, o que durou aproximadamente oito anos.

Ela estava constantemente oscilando entre dois significados antagônicos de significantes diferentes: um, de conotação positiva, em referência ao pai; outro, de conotação negativa, era trazido em forma de um dito materno. A partir de um pequeno deslizamento na cadeia de significantes, mencionou ser tratada com deferência pelas pessoas ao seu redor.

Tivemos oportunidade de constatar que a paciente havia estabelecido contato com os demais membros do grupo fora das sessões, passando a chamá-los de companheiros. No grupo, era a única que falava sempre em tom de depoimento e suas primeiras palavras eram frequentemente: "Estou limpa há 24h", indicando desse modo que o alimento era, para ela, o equivalente de uma 'droga'. Sua compulsão equivalia à drogadicção. Com mais ou menos oito meses de acompanhamento, seu pai faleceu. Ficou abatida, mas não faltou aos encontros. Dizia estar mal, entretanto, dizia também que se mantinha intacta, outro significante usado

\footnotetext{
${ }^{1}$ Referimo-nos aqui ao Serviço de Psicologia do Hospital Federal dos Servidores do Estado (HFSE-RJ).

2 Trata-se de um nome fictício.
} 
com frequência e que parecia corresponder ao deslizamento da série iniciada com o significante limpa.

$\mathrm{Na}$ maioria das vezes em que lançava mão desses artifícios linguísticos, Maria apresentava-se altiva, dona de si, e vangloriava-se de seu firme propósito de emagrecimento. Mas a oralidade também se fazia presente através da associação entre a dificuldade de falar e de parar de comer em excesso. Quando ela trazia o tema alimentar de forma direta para a dinâmica do grupo, podíamos perceber os significantes comida e porcaria assumindo diferentes significados e fazendo referência aos processos edípicos envolvidos. Foram incontáveis as repetições de que o pai adoeceu cedo porque só comia porcaria, e que seu excesso de peso era resultado de só comer porcaria, assim como ele. Nessa mesma linha, ela também dizia que a pessoa é aquilo que come, repetindo o título de um livro popular. Ao ser indagada sobre tal afirmação, ressaltou que a comida é fator determinante no destino das pessoas.

Em um dos encontros, disse que seu marido ainda iria conhecer a mulher tanquinho que ele tanto queria. O grupo adotou esse significante e o sintagma metafórico "mulher tanquinho" começou a reaparecer em sua fala, como nas declarações: Esta semana emagreci 500 gramas, a mulher tanquinho está chegando; fico pensando o que farei quando olhar para mim e puder ver a mulher tanquinho.

Em 2009, quando iniciou o programa de cirurgia bariátrica no HFSE-RJ, estava trabalhando em uma corretora de seguros, havia emagrecido $33 \mathrm{~kg}$. Observa-se um novo deslizar metonímico de comedora para corretora. Exercendo a função de assessorar valores, comercializar títulos, ou monopolizar transações envolvendo ganhos e perdas em uma companhia de seguros, Maria, nesse período, mantinha um controle ponderal sistemático. Perdia peso de forma lenta, porém gradualmente, sem as recidivas habituais. E foi encaminhada para a gastroplastia.

O primeiro ano depois da cirurgia foi muito difícil. Entristeceu, perdeu a altivez, não saía mais de casa, não se divertia. Dizia estar voltada para si mesma, mas não faltava as sessões. Reconhecia-se em dúvida sobre tudo: trabalho, casamento e opção religiosa. Perdia peso rapidamente, o que a assustava, o fato de estar com medo era seu assunto principal. Indagada sobre isso, respondia que achava que era medo de se arrepender, medo de morrer, de ficar doente. Nas sessões subsequentes, pôde falar sobre sua preocupação em chamar a 
atenção dos homens na rua, pois tinha medo de se apaixonar por outro homem que não fosse o seu marido. E recordou-se do uniforme que precisou fazer para a feira de autopeças e disse: Eu que decidi que não seria mais a velha do conjuntinho, agora estou com medo da mulher tanquinho.

Com o prosseguimento das sessões, estava mais adaptada às limitações da dieta que lhe era imposta pela cirurgia, já não apresentava sinais claros de depressão e, por orientação médica, começou a correr com o objetivo de combater a flacidez. No início, duas vezes por semana, depois três. Em seguida, tornou-se uma corredora, inclusive de maratona. Algum tempo depois, parou de correr e interrompeu o tratamento, retornando apenas para mostrar a medalha que ganhara. Disse que se sentia bem e que estava aceitando os convites que lhe eram feitos para dar palestras sobre sua experiência de libertação da obesidade.

\section{Uma leitura psicanalítica}

Apresentaremos a seguir três deduções que, a nosso ver, explicitam três possibilidades de leitura ou interpretação psicanalítica do que aconteceu com esse sujeito.

\section{Desejos antinômicos com sustentação narcísica}

Acreditamos ser lícito afirmar a existência de uma sustentação narcísica dos desejos, todavia antinômicos, apresentados durante o percurso dos tratamentos, em grupo e individual. Como ensina a psicanálise, a instância psíquica do Ideal do eu é o resultado de um processo de introjeção de um traço extraído de um objeto externo, que tanto pode ser uma abstração, quanto um ser de carne e osso, ou ainda, uma simples característica ou um detalhe, por vezes ínfimo, de um semelhante humano. Na perda do Ideal, [S1], o sujeito deve realizar um trabalho de luto, que exige tempo e para o qual ele buscará apoio no Eu ideal [i(a)], a imagem do corpo próprio que, na primeira infância, lhe propiciou uma acentuada satisfação narcísica. No entanto, quando este vazio no Simbólico, a perda do ideal, se duplica pela ausência da imagem satisfatória, tem início um processo de tristeza semelhante ao trabalho de luto.

Maria perdeu o pai e isto evidentemente a entristeceu, mas não destruiu sua capacidade de investir libido em outros objetos, nem a fez perder o amor-próprio. Ela se aproximava cada vez mais da imagem da "mulher-tanquinho", sustentando diante de si

\section{POLÊM!CA | Revista Eletronica da Ueri}


mesma e dos outros uma posição em que o significante diferente deslizava para adeferência que a engrandecia. A significação era da ordem de um valor a mais, e não a menos.

\section{A coalescência oral-escópica e o corpo materializado na palavra}

A coalescência do oral e do escópico na organização pulsional do sujeito foi o que the permitiu materializar o corpo na palavra. O oral e o escópico, a voz e o olhar são as duas formas do objeto que recebem investimento libidinal na fantasia, mas se situam em dois níveis diferentes da relação do sujeito com o Outro primordial ${ }^{3}$.

Quando Lacan (1964) estuda a cisão do olho e do olhar, assinala que o auge da angústia, em sua intensidade crescente, acontece quando o sujeito se vê no Outro desprovido do olhar, isto é, quando ele não se reconhece em sua imagem especular. Em contrapartida, o júbilo especular, o bom gozo do olhar, resulta da projeção da imagem do corpo próprio sobre os objetos do mundo, que, nesse momento, nada mais são do que reflexos do eu corporal de um determinado sujeito. Um acidente no campo do Outro, em sua função de espelho, tanto pode ocasionar a passagem do júbilo especular à inquietante estranheza da angústia mais basal. Um fenômeno imaginário de recobrimento súbito do objeto pode ocasionar o movimento inverso: da angústia ao júbilo.

Algumas frases, como a afirmação de que "a pessoa é aquilo que come" e suas variantes, assinalam a existência da coalescência oral/escópica. Por meio desta frase, o sujeito do tratamento que narramos expressava seu ser de desejo e sua identificação com o pai imaginário. Desse modo, livrava-se da culpa, pois, se o real da lei da gravidade é o que confere ao corpo seu peso, o ser falante é culpado do real, sempre que não o simboliza (DIDIER-WEILL, 1976/1997, p. 12).

Um sujeito pode não se sentir "em casa" em seu próprio corpo, pode mergulhar na depressão e experimentar a sensação de "que não pode mais erguer um corpo que se tornou excessivamente pesado" (Idem, ibid., p.20), independentemente do peso real deste. O trabalho analítico pode transmitir-lhe um movimento de reerguimento. Maria não sofreu a injunção “Emagreça, seja bela e cale-se!”, pois encontrou o alimento da palavra para-além da imagem.

\footnotetext{
${ }^{3}$ A curva desenhada por Lacan (1963/2005, p. 320) em uma das lições finais de O Seminário, livro 10, deixa ver com clareza não apenas o lugar privilegiado ocupado pela forma fálica do objeto, no ápice da mesma, como também a função separadora do falo entre os objetos da demanda (seio e fezes) e os objetos do desejo (olhar e voz).
} 
A travessia da devastação mãe-filha

Na clínica com mulheres, encontramos, via de regra, a devastação mãe-filha como um obstáculo nem sempre superável ao desenrolar do processo analítico. Para a menina, o ato de separar-se do desejo da mãe é da ordem de "uma travessia" repleta de fantasias mais ou menos persecutórias, conforme o caso.

Maria alegava sentir-se desvalorizada pelas inúmeras comparações que eram a tônica do discurso materno, por vezes irônico. Como mencionado acima, a mãe afirmava que sua corpulência era herança genética da família paterna. Buscando contrariar o desejo de emagrecimento da filha, dizia frases do tipo: "Não precisa ter o corpo das mulatas do Sargentelli!".

No entanto, Maria submeteu-se a três cirurgias plásticas reparadoras, para retirada do excesso de pele e reconstrução dos seios. Em um discurso por vezes paradoxal, ela nunca desacreditou do amor materno, mas não cessou de insistir em que era "diferente da mãe e das irmãs". Desligando-se, portanto, da obediência ao princípio da não-contradição, seu discurso nos permitiu verificar o que chamamos, com Lacan (1973), de uma participação "não-toda" (Lacan, 1973) na castração que rege a fala consciente.

Nesse ponto vale lembrar também as observações finais de Freud (1931/1932) acerca da longa duração da relação pré-edipiana mãe-filha, que encontrará o ápice na hostilidade desta última. A menina acusará a mãe de tê-la gerado como um ser faltante, sem se dar conta de que tal característica é a consequência necessária de sua geração enquanto ser falante.

Freud (1932) adjetivou a relação mãe-filha de potencialmente catastrófica. E Lacan, embora tivesse alguma discordância deste em relação à castração das mulheres, referiu-se à relação mãe-filha de forma semelhante, asseverando que,

(...) a elucubração freudiana do complexo de Édipo, que faz da mulher peixe na água, pela castração ser nela ponto de partida (Freud dixit), contrasta dolorosamente com a realidade de devastação que constitui na mulher, em sua maioria, a relação com a mãe, de quem, como mulher, ela realmente parece esperar mais substância que do pai... (LACAN, 1972/2003, p.465).

A "travessia" da devastação está longe de ser a supressão completa das lembranças e dos afetos de angústia. Ao contrário, para que sejam interrogadas as dolorosas certezas fantasmáticas, é preciso rever o catálogo das lembranças, repassá-las uma a uma. Trata-se de uma releitura em que o sujeito pode sair do lugar de vítima e responsabilizar-se pelas 
experiências e vivências que um dia registrou. Trata-se, também, de deixar cair uma imagem idealizada de mulher que muitas vezes se impõe entre mãe e filha.

Ao trabalhar sobre essa questão, Marie-Magdeleine Lessana (2000), chama a atenção para a ambiguidade do termo francês ravage, que tanto significa devastação, quanto encantamento, arrebatamento ou deslumbramento. Seu estudo nos ajuda a esclarecer a própria ambiguidade de Maria em relação aos ditos maternos. Há um confronto direto entre a filha e a mãe sobre questões da feminilidade. Este confronto se trava por meio de seus corpos, justamente no ponto em que a identificação mãe-filha se torna impossível. Nesse ponto, sobrevêm a raiva e, eventualmente, o enlouquecimento (LESSANA, 2000, p.18).

Os três fatores subjetivos cuja presença deduzimos no presente estudo, quais sejam: a coexistência no mesmo sujeito de dois desejos antinômicos sem a perda da sustentação narcícisa, a coalescência oral-escópica e a devastação mãe-filha, não necessariamente estarão presentes em todos os casos de menina ou mulheres obesas, mas merecem ser sistematicamente investigados. Há indícios de sua alta frequência na obesidade feminina. São fatores que permitem uma abordagem psicanalítica e que podem resultar em efeitos terapêuticos.

\section{Referências}

ANJOS, L. A.; VEIGA, G. V.; CASTRO I. R. R. Distribuição dos valores do índice de massa corporal da população brasileira até 25 anos. Rev. Panam Salud Publica, n.3, p.164-173,1998.

ASSOCIAÇÃO PSIQUIÁTRICA AMERICANA. Manual Diagnóstico e Estatístico de Transtornos Mentais. Ed. DSM-IV. New York: Guilford Press, 1995.

BRAY, G. A.; GREENWAY, F. L. Current andpotentialdrugs for treatmentofobesity. EndocrineReviews, n.20, p.805-875, 1999.

COMITÉ NACIONAL DE LOS ESTADOS UNIDOS. La nutrición: los lazos entre alimentación, salud y dasarrolo. Washington D.C., 1992. [Documento preparado para la Teleconferencia del Dia Mundial de la Alimentación, 16 de octubre de 1992].

CUNHA, A. G. Dicionário etimológico da língua portuguesa. 3.ed. Rio de Janeiro: Lexikon, 2007.

DIDIER-WEIL, A. Nota azul: Freud, Lacan e a Arte. Rio de Janeiro: Contra Capa Livraria Ltda., 1997.

FLANDRIN, J.; MONTANARI, M. História da alimentação. São Paulo: Estação Liberdade, 1998.

FREUD, S. (1930 [1929]). O mal-estar na civilização. Rio de Janeiro: Imago, 1976. p.13-80. (Edição Standard Brasileira das Obras Psicológicas Completas de Sigmund Freud, v.21).

\section{POLÊM!CA | Revista Eletronica da Ueri}


(1933 [1932]). Novas Conferências Introdutórias sobre psicanálise. Conf. XXXIII. Feminilidade. Rio de Janeiro: Imago, 1976. p.139-165. (Edição Standard Brasileira das Obras Psicológicas Completas de Sigmund Freud, v.22).

FUNDAÇÃO INSTITUTO BRASILEIRO DE GEOGRAFIA E ESTATÍSTICA. IBGE. Estudo Nacional da Despesa Familiar (ENDEF): consumo alimentar; antropometria. Regiões I, II, III, IV, V. Dados preliminares. Rio de Janeiro: IBGE, 1977. v.1, t.1.

GILMAN, S. L. Fat: a cultural history of obesity. Cambridge: UK Malden, MA, USA, 2010.

GRIECO, A. F. Alimentação e classes sociais no fim da Idade Média e na Renascença. In: FLANDRIN, J.; MONTANARI, M. História da alimentação. São Paulo: Estação Liberdade, 1998. p.466- 477.

JORNAL O GLOBO. Caderno Saúde. Rio de Janeiro, 23 de março de 2014.

LACAN, J. (1962-1963). O seminário, livro 10: a angústia. Rio de Janeiro: Jorge Zahar, 2005. (1972) O aturdito. In: Outros escritos. Rio de Janeiro, Jorge Zahar Ed., 2003, p. 448-497.

LESSANA, M.-M. Entre mère et fille: un ravage. Paris, ÉditionsPauvert, 2000.

OBAID, F. P. Las pulsaciones canibalísticas de la oralidad. Revista Latinoamericana de Psicopatología Fundamental, São Paulo, 16 (4), 541-554, dez. 2013.

REPETTO, G. Histórico da obesidade. In: HALPEN, A. et al. (Orgs.). Obesidade. São Paulo: Editora Lemos, 1998. p.217-223.

ROMANELLI, G. O significado da alimentação na família: uma visão antropológica. Medicina, Ribeirão Preto, v.39, n.3, p.333-39, 2006.

Recebido em: 26/04/2015.

Aceito em: 11/05/2015. 